\title{
sciendo \\ Mathematical model for calculating fuel consumption in real effect weather for a vehicle vessel
}

doi:10.2478/mape-2019-0036

Date of submission to the Editor: $04 / 2018$

Date of acceptance by the Editor: 07/2018

MAPE 2019, volume 2, issue 1, pp. 367-374

\section{Tadeusz Szelangiewicz*}

\section{Katarzyna Żelazny}

Maritime University of Szczecin, Poland

\section{INTRODUCTION}

When operating a ship, one of the most important tasks is to forecast the ocean route. When forecasting the ocean route, the most common criteria are (Wiśniewski, 1991):

- minimization of the time voyage,

- minimizing of the fuel consumption,

- minimization of the fuel consumption with the prescribed time voyage.

Regardless of which of these criteria is used, when sailing in particularly difficult weather conditions (storm waves and high wind speed, tropical cyclones), while forecasting the navigation route, the safety of the ship, cargo and crew are also taken into account.

Forecasting of ocean routes is performed by specialized institutions using appropriate computer systems for this purpose, such as: SPOS (SPOS Program, 2009) (Ship Performance Optimization System), BON VOYAGE (Bon Voyage System, 2016, Szymański and Wiśniewski, 2016). In these systems, in addition to calculating the speed of the ship (or speed decrease) in real weather conditions, daily fuel consumption is calculated, as well as for the entire sailing route. Nowadays, forecasting fuel consumption and related exhaust emissions is very important for environmental protection and current IMO regulations (MEPC, 2009). Many publications deal with issues of fuel consumption in changing weather conditions (Geertsma et. all, 2017, Białostocki and Konovessis, 2016, Myung-II R, 2013). Most often in the publications simple algorithms are used that use fuel characteristics to calculate fuel consumption. They do not take into account different criteria for the operation of the propulsion engine to calculate the point of the propulsion system in changing weather conditions, on which depends the total resistance of the ship on the ocean route, its speed and fuel consumption.

The article presents a mathematical model for calculating fuel consumption in real weather conditions during a voyage of a ship on an oceanic route, using:

- actual, for a given drive engine, specific fuel consumption characteristics,

- various engine control options (by changing the fuel dose) in order to find the optimum working point in changing weather conditions.

\footnotetext{
*t.szelangiewicz@am.szczecin.pl
} 


\section{GENERAL MATHEMATICAL MODEL FOR CALCULATING FUEL CONSUMPTION DURING VEHICLE SHIPPING}

During a voyage in real weather conditions on a given route on the ship, apart from the resistance on calm water, there act additional forces from wind, waves and possibly from surface sea currents, Fig. 1.

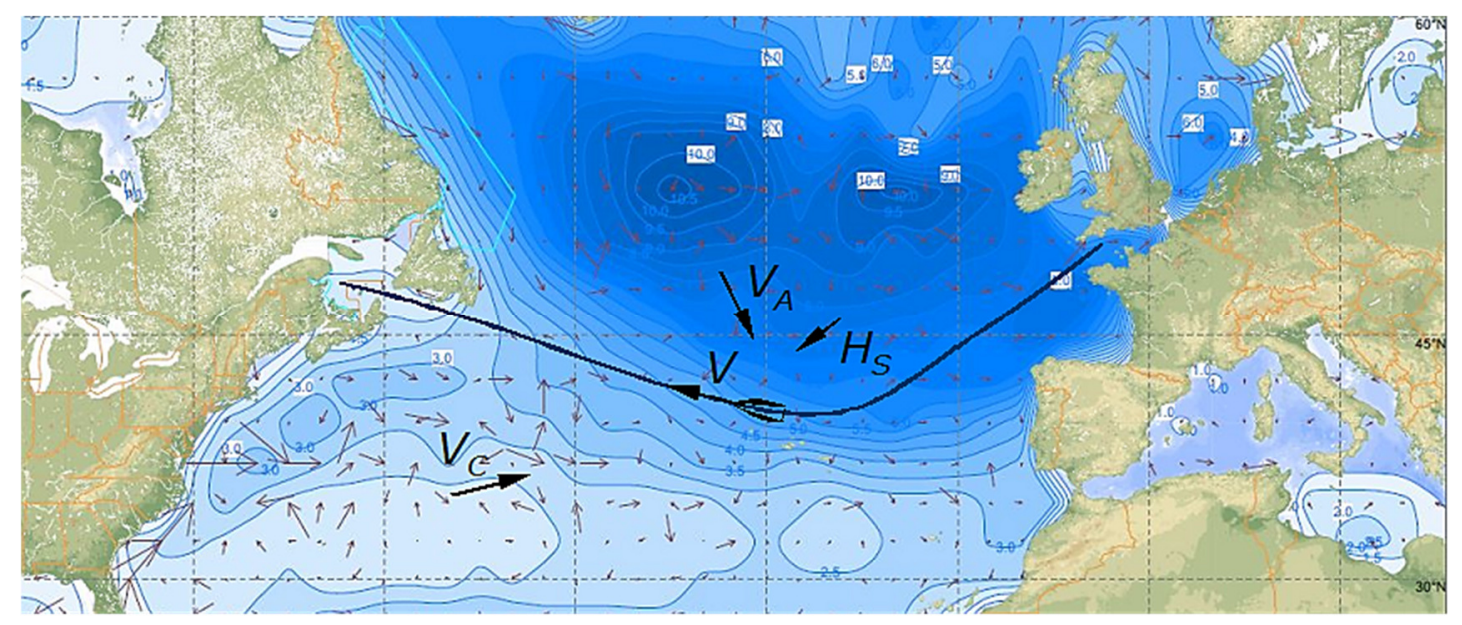

Fig. 1 An example of a shipping route and directions of the impact of the marine environment on the ship

$\left(V_{A}-\right.$ wind speed, $H_{S}-$ significant height wave, $V_{C}$ - current speed)

The total resistance of the ship in real weather conditions is equal:

$$
R_{T}=R_{V x}+\Delta R,
$$

where:

$R_{V x}$ - ship resistance in calm water,

$\Delta R$ - additional resistance to wind, waves, surface sea currents and to the deflected fin rudder keeping the course of the ship at the oblique impacts of the marine environment.

$V_{E}$ operating velocity with which the vessel can floating results from the balance between the total resistance $R_{T}$ and the thrust force $T$ of the propeller:

$$
T=\frac{R_{T}}{1-t},
$$

where:

$t$ is the suction coefficient (the value of the suction coefficient may depend on the vessel speed $t(\mathrm{~V})$.

Torque is generated on the working propeller $Q$ :

$$
Q=K_{Q} \rho_{w} D_{p}^{5} n_{p}^{2},
$$

where:

$K_{Q}$ - torque coefficient on the propeller,

$\rho_{w}$ - water density,

$D_{p}$ - diameter of the propeller,

$n_{p}$ - rotation speed of the propeller.

Between the moment $Q$ on the propeller and the power applied to the propeller $P_{D}$ is the following relationship: 


$$
P_{D}=Q \cdot 2 \pi n_{p}
$$

between power $P_{D}$ and the power of the drive motor $N$ :

$$
N=\frac{P_{D}}{\eta_{G} \cdot \eta_{S} \cdot \eta_{R T}}
$$

where:

$\eta_{G}-$ gearbox efficiency, if used,

$\eta_{S}$ - the efficiency of the shaft line,

$\eta_{R T}$ - rotational "efficiency" (rotational "efficiency" may vary depending on the speed of the ship $\eta_{R T}(V)$.

The article (Szelangiewicz and Żelazny, 2006) presents equations describing the total resistance of the ship during a voyage along the ocean route. Propeller thrust results from the speed of the ship and possible motions of the ship on the wave (mainly when the propeller emerges), and from the position of the equilibrium point between $R_{T}$ and $T$ in the field of operation of the propulsion engine (Fig. 2).

\section{CMCR}

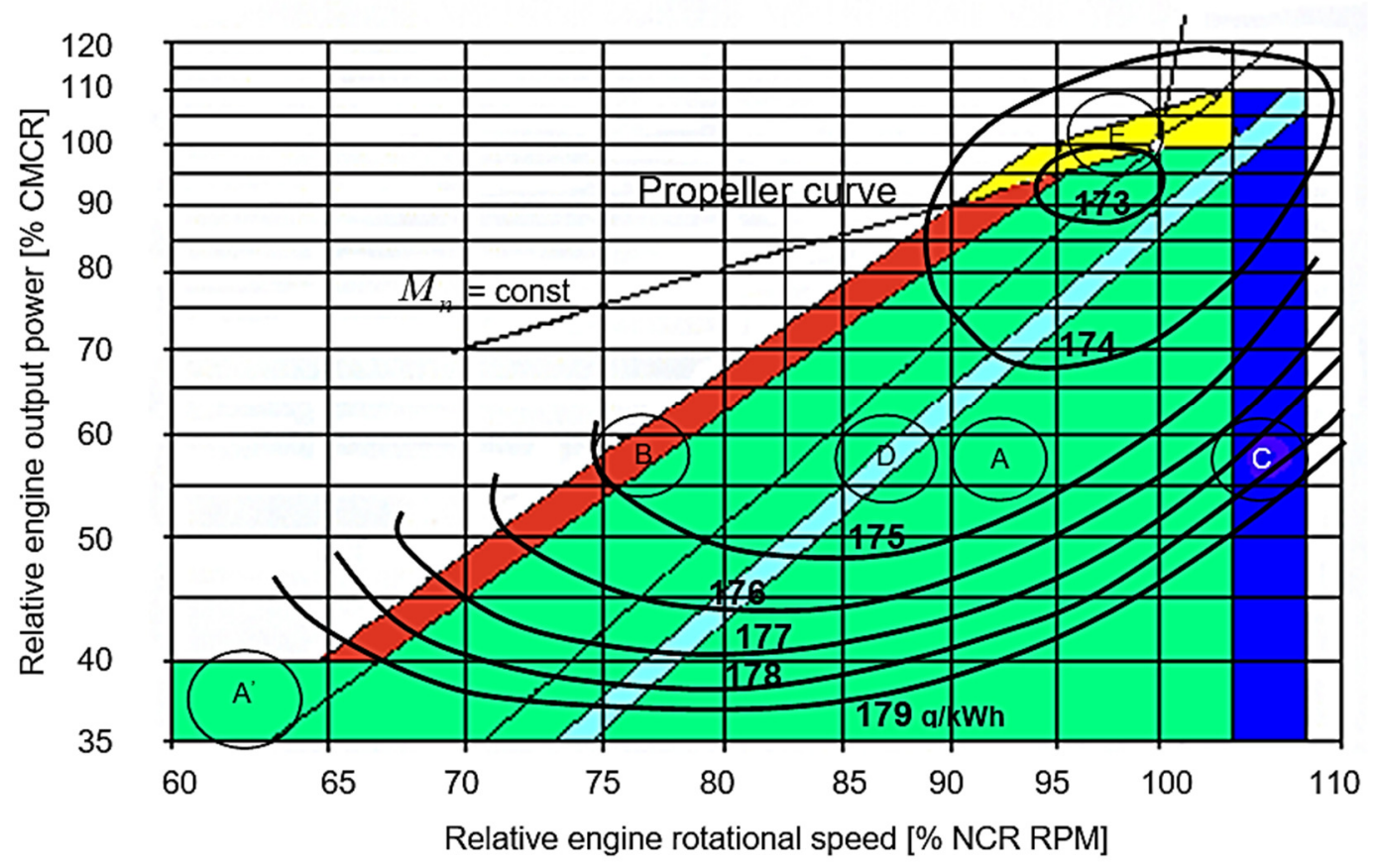

Fig. 2 The load area of an example low-speed propulsion engine

$M_{n}$ - nominal torque, A - continuous rating area (marked green),

B - engine overloading area (red), C - engine sea trial operation area (deep blue),

D - engine optimum still-water operation area (blue),

E - engine instantaneous operation area (yellow)

Fuel consumption: hourly $B_{h}$ or daily $B_{D}$ depends on the specific fuel consumption $g$ and on the power $N$ and engine speed $n$, resulting from the position of the operating point in the field of engine work, Fig. 2.

The particular areas are limited by the engine performance characteristic curve in the following from:

$$
N=k_{m} \cdot n^{m},
$$


where:

$N$ - engine output power,

$k_{m}$ - coefficient for a given characteristic curve,

$n$ - engine rotational speed,

$m$ - exponent depending on a type of engine of a given producer.

Hourly fuel consumption is as follows:

$$
B_{h}=g(N, n) \cdot N,
$$

and daily:

$$
B_{D}=\sum_{1}^{24} B_{h}
$$

where:

- $g(N, n)$ the specific fuel consumption depends on the instantaneous power $N$ and the rotational speed $n$ of the drive motor,

- $N$ instantaneous power of the drive motor.

Therefore, in order to calculate hourly or daily fuel consumption, it is necessary to know for a given engine the position of the operating point and the characteristics $g(N, n)$ of specific fuel consumption for this work point (Yuankang and Shipyard, 1993). The working point depends on the adopted criterion of engine control and on the momentary weather parameters on which the temporary, total resistance of the ship depends.

\section{Working field and characteristics propulsion}

For the designed ship, the engine power is selected so that the operating point of the drive system for the contractual speed on calm water is about 0,90 $N_{n}$ (nominal power of the engine). In real weather conditions, when the ship is affected by wind and waves, and there is additional resistance $\Delta R$ from atmospheric conditions, the operating point of the drive system will change its position in the working field of the propulsion engine.

By controlling the fuel dose (and thus the engine and screw speed), the operating point can be in the continuous work area (green field - Fig. 2) or in the area limited by motor overload (yellow or red field - Fig. 2).

The propulsion characteristics of the ship are power curves, thrust, efficiency and torque on the propeller, fuel consumption presented as a function of the rotational speed of the propeller (engine) and as a function of the ship's speed for various resistance characteristics resulting from wind, wave and sea currents.

Fig. 3 contains exemplary, calculated propulsion characteristics for a constant wind speed in an arbitrary direction in relation to the ship's direction of movement (in this case, the ship sail upwind - propulsive characteristics can be represented for any wind directions and/or wave). Such characteristics enable the correct choice of the operating point of the propulsion system in changing weather conditions or prediction of eg the maximum speed of the ship, which can be achieved with the deteriorating sea conditions. 


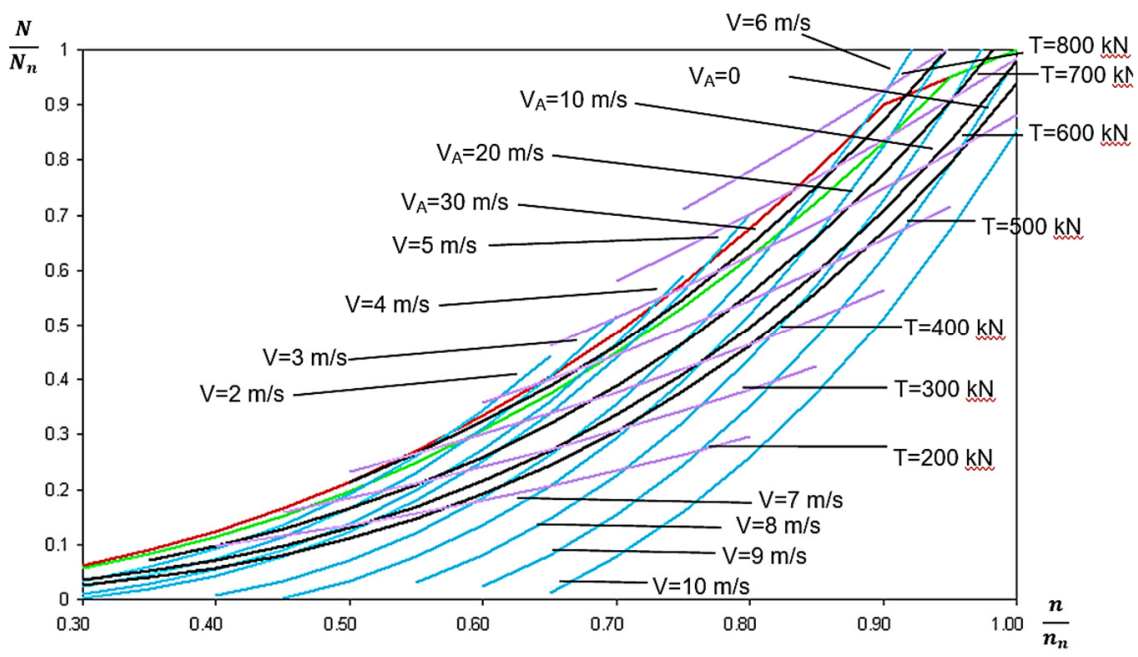

Fig. 3 Characteristics of the ship's constant speed

(container ship: $L=140.14 \mathrm{~m}, B=22.3 \mathrm{~m}, d=8.25 \mathrm{~m}, \nabla=17290 \mathrm{~m}^{3}$ ), constant thrust $T$ propeller and constant wind speed $V_{A}$

Possibility of changing the operating point of the propulsion system (fixed pitch propeller) caused by the increase of additional resistance, in this case from the wind (the ship is sailing upwind), shown in Fig. 4.

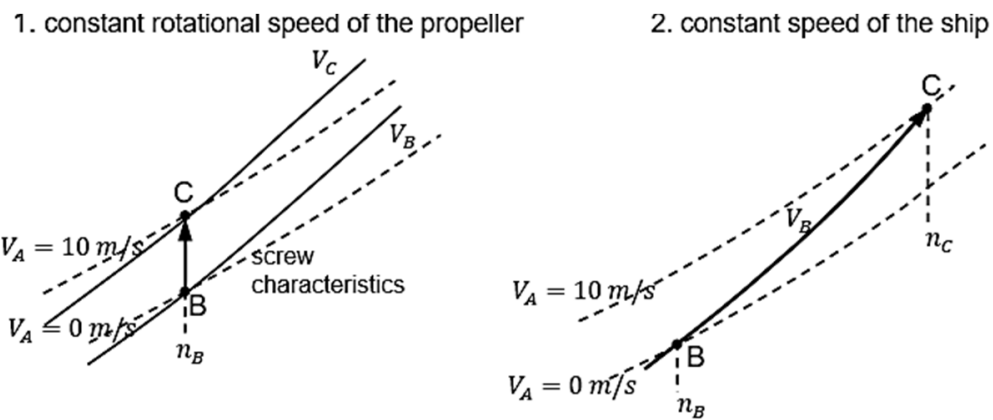

3. constant of the engine power

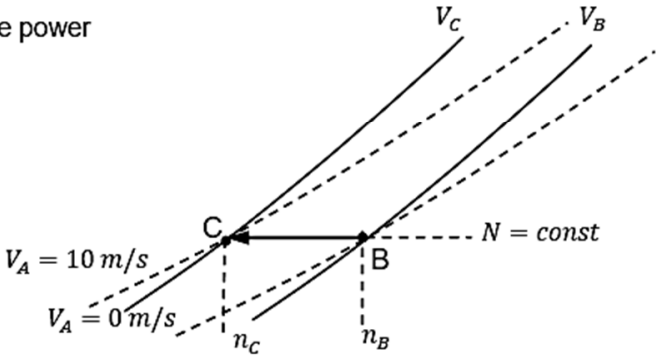

4. constant unit fuel consumption

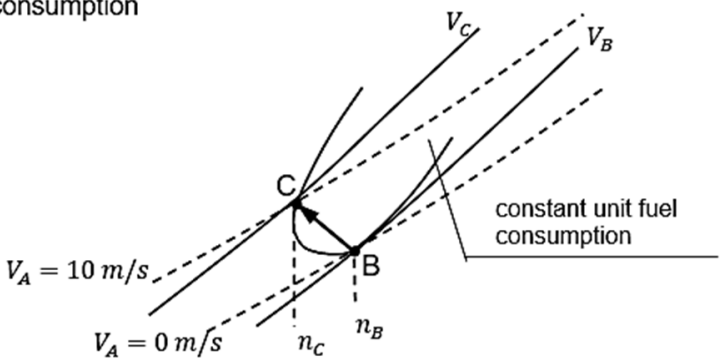

Fig. 4 Examples of changing the operating point of the propulsion system as a result of an increase in additional resistance due to weather conditions 
In this example, the vessel is in calm water in the starting position (point B) with $V_{B}$ speed and propeller speed $n_{B}$ and wind speed $V_{A}=0 \mathrm{~m} / \mathrm{s}$. Then an additional resistance arises from the up wind at the velocity $V_{A}=10 \mathrm{~m} / \mathrm{s}$ from the bow. The following paths are possible from the current work point (point $B$ ) to the new operating point (point C) of the propulsion system (Fig. 4):

1. while maintaining the constant speed $n_{B}$, the fuel dose increases (the engine power increases) until reaching the $C$ point on the $V_{A}$ characteristic, the speed of the ship drops to the value $V_{C}$;

2. while maintaining the constant speed of the $V_{B}$ ship, the fuel dose increases (engine power increases and the rotational speed is increased to $n_{C}$ ) until reaching the $\mathrm{C}$ point (the constant speed of the ship can be maintained up to the limit curve for a given engine);

3. maintaining the constant engine power, the point $C$ is reached, the ship speed to $V_{C}$ and engine speed to the ship are reduced $n_{C}$;

4. by maintaining a constant unit fuel consumption until reaching point $C$, the speed of the ship and the engine speed are reduced.

The aforementioned 4 possibilities of achieving a new work point of the propulsion system of the ship with increasing resistance - in this case - wind velocities may be used with various other assumed criteria for forecasting the ship's route, e.g.: constant speed of the ship, maximum possible speed of the ship, minimum wear fuel or constant or maximum efficiency of the propeller.

\section{RESULTS OF THE CURRENT FUEL CONSUMPTION CALCULATIONS FOR A FLOATING VESSEL IN VARIABLE WEATHER CONDITIONS}

Calculations of instantaneous fuel consumption in changing weather conditions have been made according to our own algorithm for:

- a container ship with parameters:

- $L=140.14 \mathrm{~m}, B=22.3 \mathrm{~m}, d=8.25 \mathrm{~m}, \nabla=17290 \mathrm{~m}^{3}$

- $N_{n}=6930 \mathrm{~kW}, n_{n}=2.331 / \mathrm{s}, D_{P}=5.20 \mathrm{~m}$

- using the characteristics of the specific fuel consumption of the propulsion engine installed on the ship (Fig. 2),

- various criteria (variants) of engine control by changing the fuel dose (Fig. 4) in changing weather conditions (markings of directions of the marine environment and ship's course - Fig. 5).

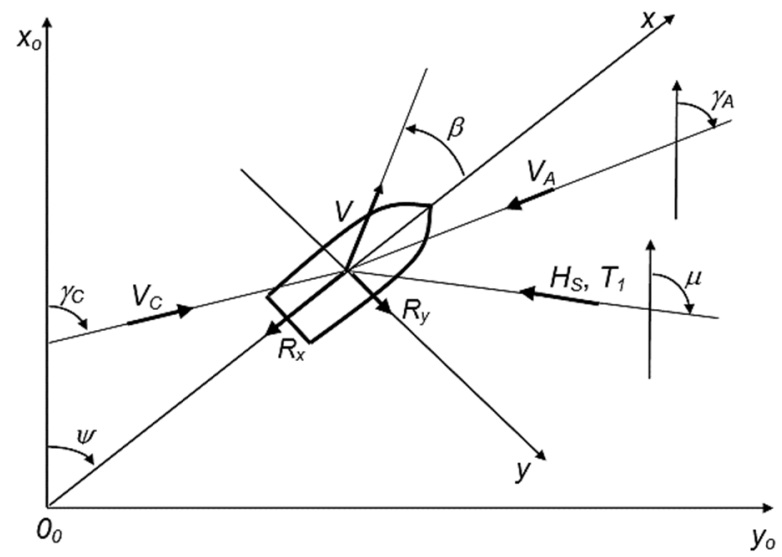

Fig. 5 Directions of the current, wind, wave and speed of the ship with the drift angle 
Calculation results of hourly fuel consumption (7) for variable weather parameters determined by Beaufort number (BN) and for four criteria, Fig. 4, are presented in Table 1.

Table 1

Hourly fuel consumption in variable weather conditions for various engine control criteria

\begin{tabular}{|c|c|c|c|c|c|}
\hline $\begin{array}{c}\text { Weather } \\
\text { parameters } \\
(\mathrm{BN})\end{array}$ & $\begin{array}{l}\text { Operation } \\
\text { parameters } \\
\text { of the ship }\end{array}$ & $\begin{array}{l}\text { Criterion } 1 \\
n_{E}=\text { const }\end{array}$ & $\begin{array}{l}\text { Criterion } 2 \\
V_{E}=\text { const }\end{array}$ & $\begin{array}{l}\text { Criterion } 3 \\
N_{E}=\text { const }\end{array}$ & $\begin{array}{r}\text { Criterion } 4 \\
g=\text { const }\end{array}$ \\
\hline 0 & $\begin{array}{c}V_{E}[\mathrm{~m} / \mathrm{s}] \\
N_{E}[\mathrm{~kW}] \\
g_{E}[\mathrm{~g} / \mathrm{kWh}] \\
B_{h}[\mathrm{~kg} / \mathrm{h}]\end{array}$ & $\begin{array}{c}16.32 \\
6046.35 \\
173.096 \\
1046.6\end{array}$ & $\begin{array}{c}16.32 \\
6046.35 \\
173.096 \\
1046.6\end{array}$ & $\begin{array}{c}16.32 \\
6046.35 \\
173.096 \\
1046.6 \\
\end{array}$ & $\begin{array}{c}16.32 \\
6046.35 \\
173.096 \\
1046.6\end{array}$ \\
\hline 1 & $\begin{array}{c}V_{E}[\mathrm{~m} / \mathrm{s}] \\
N_{E}[\mathrm{~kW}] \\
g_{E}[\mathrm{~g} / \mathrm{kWh}] \\
B_{h}[\mathrm{~kg} / \mathrm{h}]\end{array}$ & $\begin{array}{c}16.30 \\
6054.37 \\
173.087 \\
1047.9 \\
\end{array}$ & $\begin{array}{c}16.32 \\
6082.63 \\
173.091 \\
1052.8 \\
\end{array}$ & $\begin{array}{c}16.31 \\
6046.35 \\
173.099 \\
1046.6 \\
\end{array}$ & $\begin{array}{c}16.31 \\
6011.11 \\
173.096 \\
1040.5\end{array}$ \\
\hline 2 & $\begin{array}{c}V_{E}[\mathrm{~m} / \mathrm{s}] \\
N_{E}[\mathrm{~kW}] \\
g_{E}[\mathrm{~g} / \mathrm{kWh}] \\
B_{h}[\mathrm{~kg} / \mathrm{h}]\end{array}$ & $\begin{array}{c}16.28 \\
6065.37 \\
173.078 \\
1049.8\end{array}$ & $\begin{array}{c}16.32 \\
6132.63 \\
173.088 \\
1061.5\end{array}$ & $\begin{array}{c}16.30 \\
6046.35 \\
173.102 \\
1046.6\end{array}$ & $\begin{array}{c}16.29 \\
5976.08 \\
173.096 \\
1034.4\end{array}$ \\
\hline 3 & $\begin{array}{c}V_{E}[\mathrm{~m} / \mathrm{s}] \\
N_{E}[\mathrm{~kW}] \\
g_{E}[\mathrm{~g} / \mathrm{kWh}] \\
B_{h}[\mathrm{~kg} / \mathrm{h}]\end{array}$ & $\begin{array}{c}16.21 \\
6093.92 \\
173.070 \\
1054.7 \\
\end{array}$ & $\begin{array}{c}16.32 \\
6263.64 \\
173.088 \\
1084.2 \\
\end{array}$ & $\begin{array}{c}16.28 \\
6046.35 \\
173.105 \\
1046.7 \\
\end{array}$ & $\begin{array}{c}16.25 \\
5961.25 \\
173.096 \\
1031.9 \\
\end{array}$ \\
\hline 4 & $\begin{array}{c}V_{E}[\mathrm{~m} / \mathrm{s}] \\
N_{E}[\mathrm{~kW}] \\
g_{E}[\mathrm{~g} / \mathrm{kWh}] \\
B_{h}[\mathrm{~kg} / \mathrm{h}]\end{array}$ & $\begin{array}{c}16.12 \\
6129.17 \\
173.052 \\
1060.7\end{array}$ & $\begin{array}{c}16.32 \\
6427.61 \\
173.139 \\
1112.9\end{array}$ & $\begin{array}{c}16.26 \\
6046.35 \\
173.107 \\
1046.7\end{array}$ & $\begin{array}{c}16.19 \\
5926.62 \\
173.096 \\
1025.9\end{array}$ \\
\hline 5 & $\begin{array}{c}V_{E}[\mathrm{~m} / \mathrm{s}] \\
N_{E}[\mathrm{~kW}] \\
g_{E}[\mathrm{~g} / \mathrm{kWh}] \\
B_{h}[\mathrm{~kg} / \mathrm{h}]\end{array}$ & $\begin{array}{c}15.94 \\
6192.59 \\
173.017 \\
1071.4 \\
\end{array}$ & $\begin{array}{c}16.32 \\
6728.40 \\
173.269 \\
1165.8 \\
\end{array}$ & $\begin{array}{c}16.22 \\
6046.35 \\
173.114 \\
1046.7 \\
\end{array}$ & $\begin{array}{c}16.10 \\
173.096 \\
5892.20 \\
1019.9 \\
\end{array}$ \\
\hline 6 & $\begin{array}{c}V_{E}[\mathrm{~m} / \mathrm{s}] \\
N_{E}[\mathrm{~kW}] \\
g_{E}[\mathrm{~g} / \mathrm{kWh}] \\
B_{h}[\mathrm{~kg} / \mathrm{h}]\end{array}$ & $\begin{array}{c}15.44 \\
6409.11 \\
173.000 \\
1108.8 \\
\end{array}$ & $\begin{array}{c}15.77 \\
6881.14 \\
173.304 \\
1192.5 \\
\end{array}$ & $\begin{array}{c}15.79 \\
6046.35 \\
173.177 \\
1047.1 \\
\end{array}$ & $\begin{array}{c}15.11 \\
173.096 \\
5871.88 \\
1016.4 \\
\end{array}$ \\
\hline 7 & $\begin{array}{c}V_{E}[\mathrm{~m} / \mathrm{s}] \\
N_{E}[\mathrm{~kW}] \\
g_{E}[\mathrm{~g} / \mathrm{kWh}] \\
B_{h}[\mathrm{~kg} / \mathrm{h}]\end{array}$ & $\begin{array}{c}12.93 \\
6702.75 \\
173.391 \\
1162.2 \\
\end{array}$ & $\begin{array}{c}12.93 \\
6702.75 \\
173.391 \\
1162.2\end{array}$ & $\begin{array}{c}14.53 \\
6046.35 \\
173.800 \\
1050.9\end{array}$ & $\begin{array}{c}14.30 \\
173.096 \\
5892.40 \\
1020.0\end{array}$ \\
\hline 8 & $\begin{array}{c}V_{E}[\mathrm{~m} / \mathrm{s}] \\
N_{E}[\mathrm{~kW}] \\
g_{E}[\mathrm{~g} / \mathrm{kWh}] \\
B_{h}[\mathrm{~kg} / \mathrm{h}]\end{array}$ & $\begin{array}{c}8.19 \\
4332.62 \\
174.704 \\
756.9 \\
\end{array}$ & $\begin{array}{c}8.19 \\
4332.62 \\
174.704 \\
756.9 \\
\end{array}$ & $\begin{array}{c}11.66 \\
4232.45 \\
174.585 \\
738.9 \\
\end{array}$ & $\begin{array}{c}11.60 \\
174.113 \\
4332.50 \\
754.3 \\
\end{array}$ \\
\hline
\end{tabular}

\section{CONCLUSIONS}

1. The results of calculations included in Table 1 have been made for variable weather parameters (wind, wave) assuming that the ship is going upwind and wave. Such calculations can also be made for any wind, wave and sea current directions relative to the ship's heading (Fig. 5).

2. Calculations of fuel consumption, ship speed and engine power are carried out assuming that the operating point of the propulsion system is located in the field of continuous operation (green field - Fig. 2) or on its limit (between green field and red - engine overload). 
3. The calculations made (Table 1) show that the unit fuel consumption $g_{E}$, as well as the hourly $B_{h} \mathrm{~h}$ fuel consumption, do not change to a large extent under different weather conditions (BN). However, the speed of the ship changes to a large extent.

4. Changes in the speed of the ship, using different criteria (Fig. 4) cause that the total fuel consumption for the whole route (Fig. 1) may be different depending on the criterion used to select a shipping route.

\section{REFEENCES}

Wiśniewski, B. (1991). Problemy wyboru drogi morskiej. Gdańsk: Wydawnictwo Morskie.

Program SPOS Fleet Management (2009). Meteo Consult BV, The Netherlands, V. 7.0.0.1.

Bon Voyage System (BVS) voyage optimization software (2016). Applied Weather Technologies (AWT), Kifer Court. Sunnyvale CA 94086. V. 7.1.

Szymański, M. and Wiśniewski, B. (2016). Application of Bon Voyage 7.0 (AWT) to programming of an ocean route of post-Panamax container vessel in transpacific voyage Seattle - Pusan 26.08.2015, 1600UTC-05.09.2015, 2100UTC. Scientific Journals of the Maritime University of Szczecin - Zeszyty Naukowe Akademii Morskiej w Szczecinie, 48(120), pp. 182-186.

MEPC.1/Circ.681 (2009). Interim Guidelines on the Method of Calculation of the Energy Efficiency Design Indes for New Ship's. International Maritime Organization.

Geertsma, R.D., Negenborn, R.R., Visser, K. and Hopman, J.J. (2017). Pitch control for ships with diesel mechanical and hybrid propulsion: Modelling, validation and performance quantification. Applied Energy, 206(15), pp. 1609-1631.

Białostocki, N. and Konovessis, D. (2016). On the estimation of ship fuel consumption and speed curve: A statistical approach. Journal of Ocean Engineering and Science, 7(2), pp. 157-166.

Myung-II R. (2013). Determination of an economical shipping route considering the effects of sea state for lower fuel consumption. International Journal of Naval Architecture and Ocean Engineering, 5(2), pp. 246-262.

Szelangiewicz, T. and Żelazny, K. (2006). Calculation of the Mean Long-Term Service Speed of Transport Ship, Part I: Resistance of Ship Sailing on Regular Shipping Route in Real Weather Conditions. Polish Maritime Research, 4(50), pp. 23-31.

Yuankang, Z. and Shipyard S. (1993). Estimation for power and specific fuel consumption for a vessel during voyage. In: 20th International Congres on Combustion Engines. London: CIMAC.

Abstract. During ship operation, one of the most important tasks is forecasting the ocean route. One of the criteria for forecasting is the minimum fuel consumption. Fuel consumption and associated emissions are also very important for other criteria. In common use, as well as in various publications, the results of calculations of fuel consumption obtained from simplified algorithms are presented. The article presents a mathematical model for calculating fuel consumption for a floating vessel in various weather conditions. In this model different criteria for controlling the propulsion engine were used by changing the fuel dose. The results of the calculations included include: fuel consumption, power of the propulsion engine and operating speed of the ship in varying weather conditions

Keywords: fuel consumption, engine control criteria, engine power, ship speed, wind and wave effects 